\title{
Thyroid 'incidentaloma'
}

\section{Nicola Solomon}

\section{THYROID NODULES}

Thyroid nodules are common. The estimated prevalence of palpable nodules ranges from 3\%-7\%, ${ }^{(1)}$ depending on the method of detection used, ${ }^{(2)}$ and non-palpable thyroid nodules are even more common, with prevalence estimated at $20 \%$ $76 \%$ of the general population on ultrasound (ultrasound), and $50 \%$ at autopsy. ${ }^{(3)}$

Nodules are more common in the elderly, women, those with iodine deficiency and those with a history of radiation exposure. They can be both benign and malignant.

The primary aim of investigation of thyroid nodules is the exclusion of malignant thyroid lesions.(1) Although thyroid cancer is the most malignant endocrine tumour, the British Thyroid Association (BTA) says it represents only about $1 \%$ of all malignancies, ${ }^{(4)}$ and the vast majority of thyroid nodules are benign. For adults with differentiated thyroid cancer, longterm outcome for those treated is usually good, with $80-90 \%$ tenyear survival. However, $5-20 \%$ of patients develop regional recurrences, $10-15 \%$ distant metastases and $9 \%$ of those diagnosed with thyroid cancer die of their disease.

The most common presentation of thyroid cancer is a newly discovered palpable thyroid nodule, or an increase in size of a pre-existing nodule. However, most patients (95\%) with this presentation have benign disease. ${ }^{(4)}$

The BTA guidelines suggest the following scheme for investigation and referral of suspected thyroid cancer:

- Patients with a nodule/goitre that has not changed for years and who have no other worrying features, and patients with non-palpable asymptomatic nodules $<1 \mathrm{~cm}$ in diameter without worrying features, may be managed in primary care.

- Patients with abnormal thyroid function tests (TFT) should be referred to an endocrinologist.

- Patients with sudden onset pain in a thyroid lump, or newly presenting lump increasing in size over months, should have a non-urgent referral to a specialist.

- Urgent referral (within two weeks) is indicated for unexplained hoarseness or voice changes with a goitre, a thyroid nodule in a child, cervical lymphadenopathy, or a thyroid nodule which rapidly enlarges over weeks.

- Immediate referral should be given to those with stridor.

Investigations should include full physical examination, review of thyroid function tests, and fine-needle aspiration (FNA) cytology with or without ultrasound guidance.

\section{INCIDENTALOMATA}

Most patients with thyroid nodules have few symptoms. This means nodules are often discovered incidentally, on examination, carotid doppler studies, or other imaging studies done for unrelated reasons. (1) A mass discovered on imaging studies performed for unrelated reasons, is for the purposes of this article termed an 'incidentaloma'. [plural incidentalomata Ed!] Masses may also be found during routine examination of the neck for other medical problems, ${ }^{(5)}$ although the term incidentaloma is sometimes reserved for those nodules which are not clinically palpable.

Thyroid incidentalomata may be picked up on several different types of imaging, including:

- Ultrasound.

- Carotid duplex scans.

- Computed tomography (CT) scanning (fewer incidentalomata are detected on CT than ultrasound, and there are no reliable distinguishing features). ${ }^{3}$

- Positron emission tomography (PET) scans (less likely to detect a thyroid lesion, but greater degree of specificity for thyroid cancer). ${ }^{(3)}$

The incidence rises with age: almost $60 \%$ of individuals at age 60 have an incidentaloma of the thyroid. ${ }^{(6)}$ Most of these are

$<2 \mathrm{~cm}$, and clinically non-palpable. ${ }^{(5)}$ Most are benign, however a small proportion (5-10\%) may harbour a low-grade malignancy, such as papillary or follicular thyroid carcinoma. ${ }^{(5)}$ In most centres, once the diagnosis of an incidentaloma is made, further investigation is carried out to exclude malignancy. However, whilst guidelines exist for the treatment of palpable thyroid lumps, there is no clear guideline or standard practice for managing thyroid incidentaloma, and so threshold for investigation varies between clinicians. ${ }^{(3.5)}$

The aim of this review is to look at and evaluate the existing guidelines for the investigation of thyroid incidentaloma. To do this, I will consider published evidence relating to management strategies for incidentaloma, and the management of incidentaloma discovered within the University Hospitals of Morecambe Bay NHS Foundation Trust (UHMBT).

\section{INCIDENCE}

As elsewhere, in UHMBT thyroid incidentalomata are not uncommon. A computer search of all thyroid ultrasoundguided FNA biopsies from 5 April 2007 to 2 March 201 I revealed that, out of 82 patients who underwent ultrasoundguided FNA of the thyroid, 17 (21\%) of these were on thyroid nodules discovered during imaging for unrelated purposes The majority of thyroid incidentalomata were found during carotid doppler studies.

Unfortunately, it was not possible to identify all incidentalomata found on imaging during this time period as, due to the limitations of the system, incidentalomata could only be picked up at the point where ultrasound-guided FNA was carried out, thus excluding cases in which FNA was deemed unnecessary. It is therefore impossible from this data to estimate the total number of thyroid incidentalomata found during this period of 


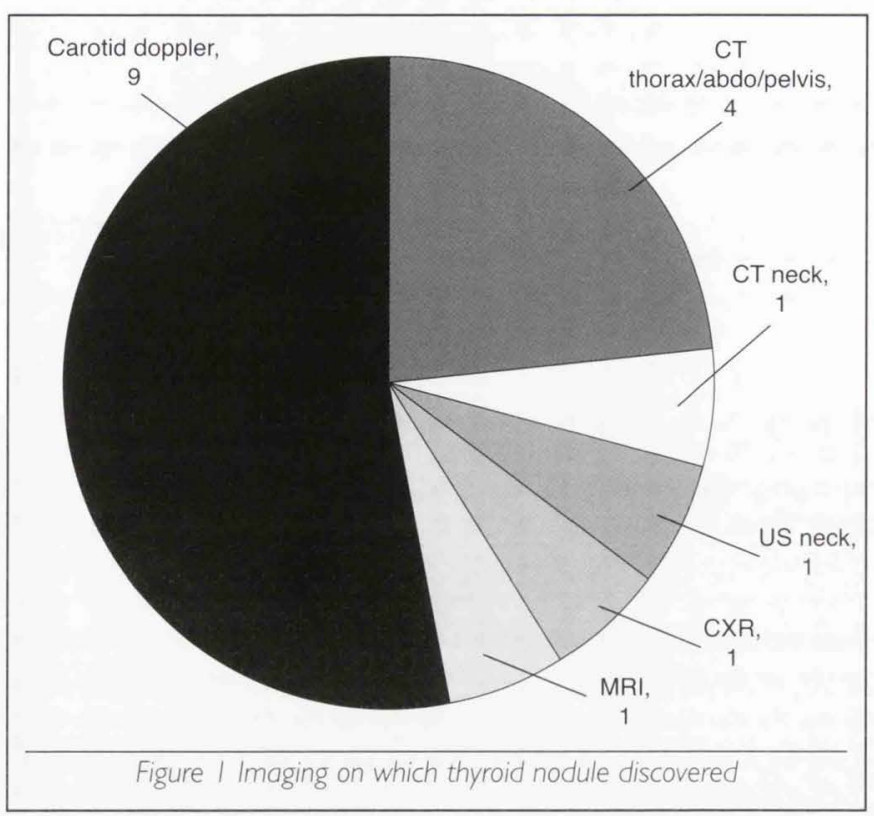

time, as it is likely that many did not undergo FNA. It is also impossible to tell what criteria, if any, were used to distinguish which would be investigated with FNA and which followed up with thyroid ultrasound only or managed in primary care. However, as table I below shows, all of the thyroid nodules which underwent FNA were over $1.6 \mathrm{~cm}$ in diameter, and many of them had ultrasound characteristics which have described as 'worrisome', such as microcalcifications and a solid appearance.

Of those incidentalomata which underwent ultrasound-guided FNA, the majority were classified as C2, benign, on cytology.

\begin{tabular}{|c|c|}
\hline $\begin{array}{l}\text { Size of thyroid } \\
\text { swelling }\end{array}$ & Characteristics \\
\hline $3.3 \mathrm{~cm}$ & Cystic degenerations and ?microcalcifications \\
\hline $3 \mathrm{~cm}$ & Solid and cystic \\
\hline $1.7 \mathrm{~cm}$ & \\
\hline $2.3 \mathrm{~cm}$ & $\begin{array}{l}\text { Multiple small nodules right lobe, one dominant } \\
\text { in LT lobe }\end{array}$ \\
\hline$>2.5 \mathrm{~cm}$ & Two large nodules right lobe, LT lobe removed \\
\hline $3.3 \mathrm{~cm}$ & Several nodules $1.4 \mathrm{~cm}, 3.3 \mathrm{~cm}$. Likely MNG \\
\hline $3.4 \mathrm{~cm}$ & $\begin{array}{l}\text { Enlarged right lobe } 3.4 \times 3.4 \times 4.5 \mathrm{~cm} \text { with large } \\
\text { heterogeneous nodule within. MNG }\end{array}$ \\
\hline $5 \mathrm{~cm}$ & Mixed echogenicity nodule \\
\hline $4.2 \mathrm{~cm}$ & $\begin{array}{l}\text { Cyst with calcification, thicker irregular wall. } \\
\text { Second nodule with hyperechoic area }\end{array}$ \\
\hline $1.6 \mathrm{~cm}$ & Cyst with solid area \\
\hline $9 \mathrm{~cm}$ & $\begin{array}{l}\text { Mixed echo pattern, calcifications, irregular } \\
\text { outline, extending retrosternally }\end{array}$ \\
\hline $1.9 \mathrm{~cm}$ & Small nodules and one dominant nodule \\
\hline $5.9 \mathrm{~cm}$ & $\begin{array}{l}\text { Tracheal deviation, few areas of nodular } \\
\text { calcification }\end{array}$ \\
\hline $6.4 \mathrm{~cm}$ & $50 \%$ increase in size over nine months \\
\hline $4 \mathrm{~cm}$ & Well-defined, solid \\
\hline $3.7 \mathrm{~cm}$ & $\begin{array}{l}\text { Mixed density, ill-defined, tracheal displacement, } \\
\text { lymphadenopathy, multiple nodules }\end{array}$ \\
\hline $2.2 \mathrm{~cm}$ & Well-defined nodule, peripheral calcification \\
\hline
\end{tabular}

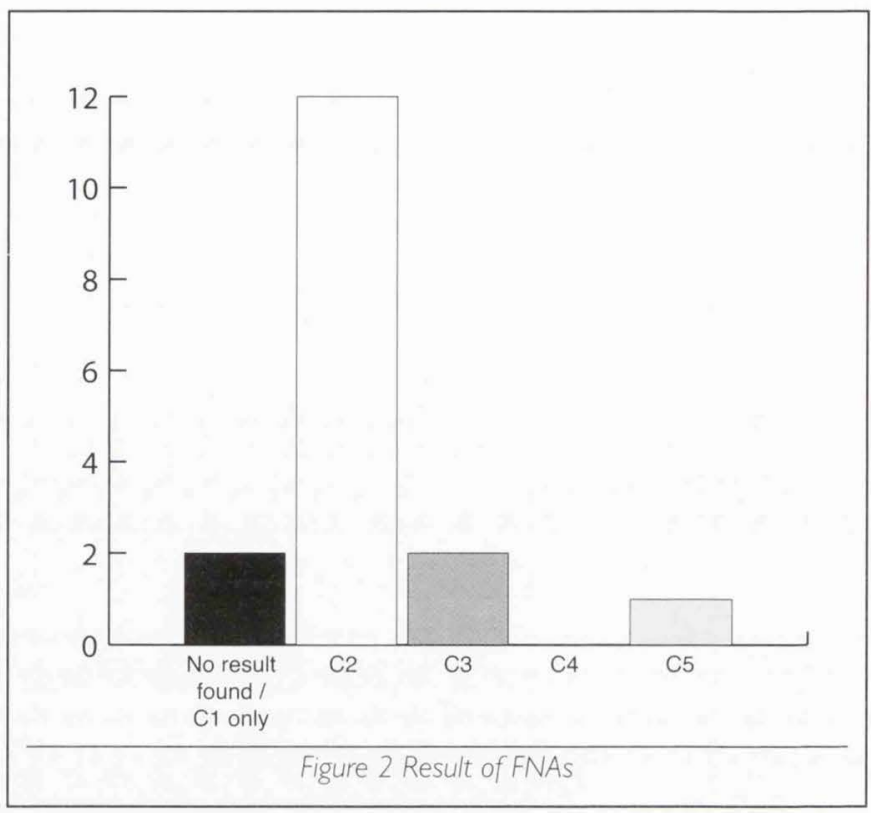

Only three were found to be suspicious, with two returning as C3, and one returning as C5 cytology. All of those discovered on carotid doppler were found to be benign.

One of those that came back as C3 was discovered on a chest $X$-ray for atrial fibrillation, on which the trachea was noted to be deviated due to a large goitre. This was initially followed up with six-monthly ultrasound scans, showing a $6.5 \mathrm{~cm}$ thyroid nodule with irregular calcifications, before undergoing FNA. The other C3 incidentaloma was discovered on a magnetic resonance imaging (MRI) of the cervical spine. This was followed up by ultrasound every six months for one year, and showed a $50 \%$ increase in size before FNA was arranged. We do not yet, as of writing this article, have details of outcome on these two cases

The C5 FNA was done after ultrasound of the neck was carried out for a lipoma. What was described as 'a hugely enlarged right-sided thyroid lobe, irregular in outline and of mixed echopattern with internal calcifications... measuring over $9 \mathrm{~cm}$... and encroaching upon both right jugular and common carotid artery... and extending retrosternally' was incidentally discovered and found to be anaplastic primary thyroid carcinoma. This patient underwent total thyroidectomy within a month.

Of the 17 patients, only two went on to undergo surgery. One of these was the patient with anaplastic primary thyroid carcinoma. The other was a patient with benign cytology who subsequently became thyrotoxic due to a solitary function nodule. There were no histology results on the system or evidence in patients' notes which indicated any others required surgical or medical intervention. Presumably those patients with benign cytology were discharged back to their general practitioner (GP), whilst those with C3 cytology await further follow-up.

This small survey gives a brief overview of the characteristics of thyroid incidentalomata in the UHMBT area; however, it is not without its limitations. At the very least, our report can be criticised for confusing the truly 'incidental' ie symptomless and undetectable on clinical examination, with the larger lesions that were detected radiologicaily and needed subsequent investigation. The discovery of a $\mathrm{C} 5$ and two $\mathrm{C} 3$ nodules, which 


\begin{tabular}{|l|l|}
\hline $\begin{array}{l}\text { Imaging on } \\
\text { which found }\end{array}$ & FNA finding \\
\hline Carotid doppler & $\mathrm{Cl}$ \\
\hline Carotid doppler & $\mathrm{C} 2$ \\
\hline Carotid doppler & $\mathrm{C} 2$ - Multinodular goitre \\
\hline CT thorax/abdo/pelvis & $\mathrm{C} 2-$ Subacute thyroiditis \\
\hline Carotid doppler & $\begin{array}{l}\mathrm{Cl}, \mathrm{C} 2-\text { Colloid nodular goitre } \\
\text { (CNG) }\end{array}$ \\
\hline Carotid doppler & $\mathrm{C} 2-$ CNG \\
\hline $\begin{array}{l}\text { CT chest/abdo/pelvis } \\
\text { and contrast }\end{array}$ & $\mathrm{C} 2-$ CNG \\
\hline Carotid doppler & $\mathrm{C} 2-$ CNG \\
\hline Carotid doppler & $\mathrm{C} 2$ \\
\hline Carotid doppler & $\mathrm{C} 2-$ Cyst without atypical cells \\
\hline $\begin{array}{l}\text { Ultrasound neck } \\
\text { for lipoma }\end{array}$ & $\begin{array}{l}\mathrm{Cl}, \mathrm{C} 5-\text { Anaplastic } \\
\text { primary thyroid Carcinoma }\end{array}$ \\
\hline Carotid doppler & $\mathrm{C} 2-$ CNG \\
\hline CXR & $\begin{array}{l}\text { C3 }- \text { No convincing evidence of } \\
\text { Ca, follicular lesion with hurtle cell } \\
\text { change }\end{array}$ \\
\hline MRI & C3 - Hurtle cell, follicular lesion \\
\hline $\begin{array}{l}\text { CT chest/abdo/pelvis } \\
\text { and contrast }\end{array}$ & C2 \\
\hline $\begin{array}{l}\text { CT chest/abdo/ } \\
\text { pelvis and contrast }\end{array}$ & C2 \\
\hline CT neck & No result available \\
\hline & FNA results from 17 incidentalomato \\
\hline
\end{tabular}

may not otherwise have been picked up until later, shows that FNA investigation is important in at least some incidentally discovered thyroid nodules. However, what criteria should be used to identify such cases is unclear.

\section{EXISTING GUIDELINES}

An internet search for published guidelines for the treatment of thyroid nodules revealed guidelines from the American Thyroid Association (ATA), ${ }^{(7)}$ the BTA, ${ }^{(4)}$ and a joint guideline from the American Association of Clinical Endocrinologists, Associazione Medici Endocrinologi and European Thyroid Association (AACE/AME/ETA), (1) was undertaken for the purposes of the study. These guideline scan be summarised as follows:

- Thyroid lesions discovered on CT or MRI have an uncertain risk of malignancy and should undergo ultrasound evaluation.

- Nodules found on I8F-fluorodeoxyglucose PET are rare but have a high risk of malignancy and should undergo ultrasound and FNA biopsy promptly.

- Tc99m technetium scan detected lesions are high risk for malignancy and should be evaluation by ultrasound.

- Only nodules $>1 \mathrm{~cm}$ should be evaluated, as they have a greater potential to be clinical significant cancer.

- Nodules $<1 \mathrm{~cm}$ with suspicious ultrasound, lymphadenopathy, history of head/neck radiation or thyroid cancer in a first degree relative should be further evaluated.

- Nodules $<1 \mathrm{~cm}$ without worrying features should be followed up in primary care.
In addition the ATA guidelines include an algcrithm for evaluation and treatment of a thyroid nodule, detected by either palpation or imaging, and guidelines as to when to perform an FNA based on clinical and ultrasound findings.

In addition to guidelines, several published reviews evaluate and recommend management strategies for thyroid incidentaloma. These are based on the characteristics of the lesion and the likelihood of malignant disease.

It is established that FNA is the 'gold standard' for diagnosis of thyroid malignancy.(2) However, current imaging can detect nodules as small as $2 \mathrm{~mm}$, and whether such non-palpable incidental lesions should undergo FNA or not is in doubt. Whilst it is unlikely to be useful or cost effective to perform ultrasound-guided FNA on all thyroid incidentalomata, opinions vary about the clinical significance of thyroid microcarcinomas. Malignancy of thyroid nodules discovered incidentally by ultrasound is likely to be low.(2) Clinically relevant thyroid carcinoma is rare, $1-2 \%$ of all carcinomas, ${ }^{(2)}$ and whilst thyroid cancer rates have increased 2.4 fold in the last decade ${ }^{(8)}$ there is no corresponding increase in mortality rates. ${ }^{(5)}$ Papillary thyroid microscopic cancers (PTMC) are prevalent in most populations, with autopsy rates between $3-22 \%{ }^{(9)}$ The question remains whether these microscopic carcinomas have implications on patient outcome, or if, as one recent study suggests, most people "live with these cancers, grow with them, and probably die with them rather than of them.'.(5)

In his review of thyroid incidentaloma, the author of one study agrees that if there is ultrasound evidence suggestive of malignancy, cytological evaluation is indicated. ${ }^{(2)}$ In those without such features, follow-up should include clinical and ultrasound evaluation. ${ }^{2}$

Another study also suggests a similar management plan. ${ }^{(3)}$

- Lesions $<5 \mathrm{~mm}$ should be left alone in the absence of suspicious radiological features.

- Lesions 5-10 mm should be observed without performing FNA.

- FNA is justified for nodules $5-10 \mathrm{~mm}$ if they significantly enlarge at the interval scan or there is one worrisome ultrasound feature

\section{microcalcification}

solid

central flow

lymphadenopathy

- Those that don't have FNA should be ultrasound scanned at six months, with a view to ultrasound-guided FNA on those which grow $>1 \mathrm{~cm}$ or have new suspicious features.

- Those that don't require FNA after six month should be reviewed clinically or by ultrasound at a standard interval of time, eg one year for enlargement or new worrying features.

- If still no change further review is unlikely to be effective.

- In cases where FNA is done, the subsequent follow up will of course depend upon the FNA outcome. The BTA provides guidelines which set out the recommended actions for each diagnostic outcome clearly.(4)

Given the high frequency of thyroid nodules detected on ultrasound, and the low frequency of clinically relevant thyroid malignancy, it seems likely that a conservative management strategy such as that suggested by the previous study ${ }^{(3)}$ is preferable. For incidentalomata discovered on other imaging 
techniques, such as CT, MRI or PET scans, slightly different criteria may be used, to reflect the likelihood of such lesions being malignant. Nodules discovered on PET scanning, although rare, are more likely to malignant. ${ }^{(5)}$ One management algorithm for PET incidentaloma is suggested in a recent study. ${ }^{15}$

Incidentalomata discovered on CT or MRI have an uncertain risk of malignancy, although a recent study suggests that features suspicious of malignancy include nodules $>2.5$ in diameter and calcifications..$^{(5)}$ They recommend that nodules detected on such imaging should undergo thyroid ultrasound to give more information about the nature of the thyroid nodule and if it is suspicious of malignancy, and those $>1 \mathrm{~cm}$, or $<1 \mathrm{~cm}$ with suspicious features, should undergo FNA.

Whilst guidelines and reviews do exist which consider the management of thyroid incidentaloma there does not seem to be one definitive guideline which combines all possible eventualities. I have therefore attempted to create an algorithm for the management of thyroid incidentaloma which combines ideas from all of the above mentioned guidelines and evidence (see below).

For thyroid incidentaloma in UHMBT it is unclear if any guidelines or set criteria were followed when considering which should go on to undergo ultrasound-guided FNA and which were followed up clinically or by repeat ultrasound evaluation. However, all those incidentalomata which underwent ultrasound-guided FNA do have features which suggest that the decision to undertake ultrasound-guided FNA was taken appropriately. All were over $1.6 \mathrm{~cm}$ in diameter, with a single or dominant nodule, and many had features which could be suspicious of malignancy, such as calcifications, solid areas, irregular outline, or a rapid increase in size. According to my algorithm, and the reviews and guidelines considered above, all were therefore investigated appropriately, despite the lack of guidelines.

\section{REFERENCES}

1. Gharid H, et al. American Association of Clinical Endocrinologists, Associazione Medici Endocrinologi, and European Thyroid Association Medical Guidelines for clinical practice for the diagnosis and management of thyroid nodules. Endocrine Practice 2010:16(Suppi I); I-43

2. Pinchera A.Thyroid Incidentalomata. Horm Res 2007:68 (Suppl 5); 199-20 I

3. Gough J, Scott-Coombes D, Palazzo F. Thyroid incidentaloma: An evidence-based assessment of management strategy. World J Surg 2008:32; | 26 |-8

4. British Thyroid Association, Royal College of Physicians. Guidelines for the management of thyroid cancer (Perro P, ed.). 2nd edition. Report of the Thyroid Cancer Guidelines Update Group. London: Royal College of Physicians. 2007

5. Iyer NG, et al. Thyroid incidentalomata: to treat or not to treat. Eur Arch Otorhinolaryngol 20 10:267(7);1019-26

6. Atli M, Akgul M, Saryal M, Daglar G, Yasti AC, Kama NA. Thyroid incidentalomata: prediction of malignancy and management. Int Surg 2006:91;237-44

7. Cooper D, et al. Revised American Thyroid Association management guidelines for patients with thyroid nodules and differentiated thyroid cancer. Thyroid 2009:19(1 1); |167-1214

8. Davies L, Welch HG. Increasing incidence of thyroid cancer in the United States, 1973-2002. I Am Med Assoc 2006:295;2164-67

9. Harach HR, Franssila KO, Wasenius VM. Occult papillary carcinoma of the thyroid. A 'normal' finding in Finland. A systematic autopsy study. Cancer 1985:56(3);531-8

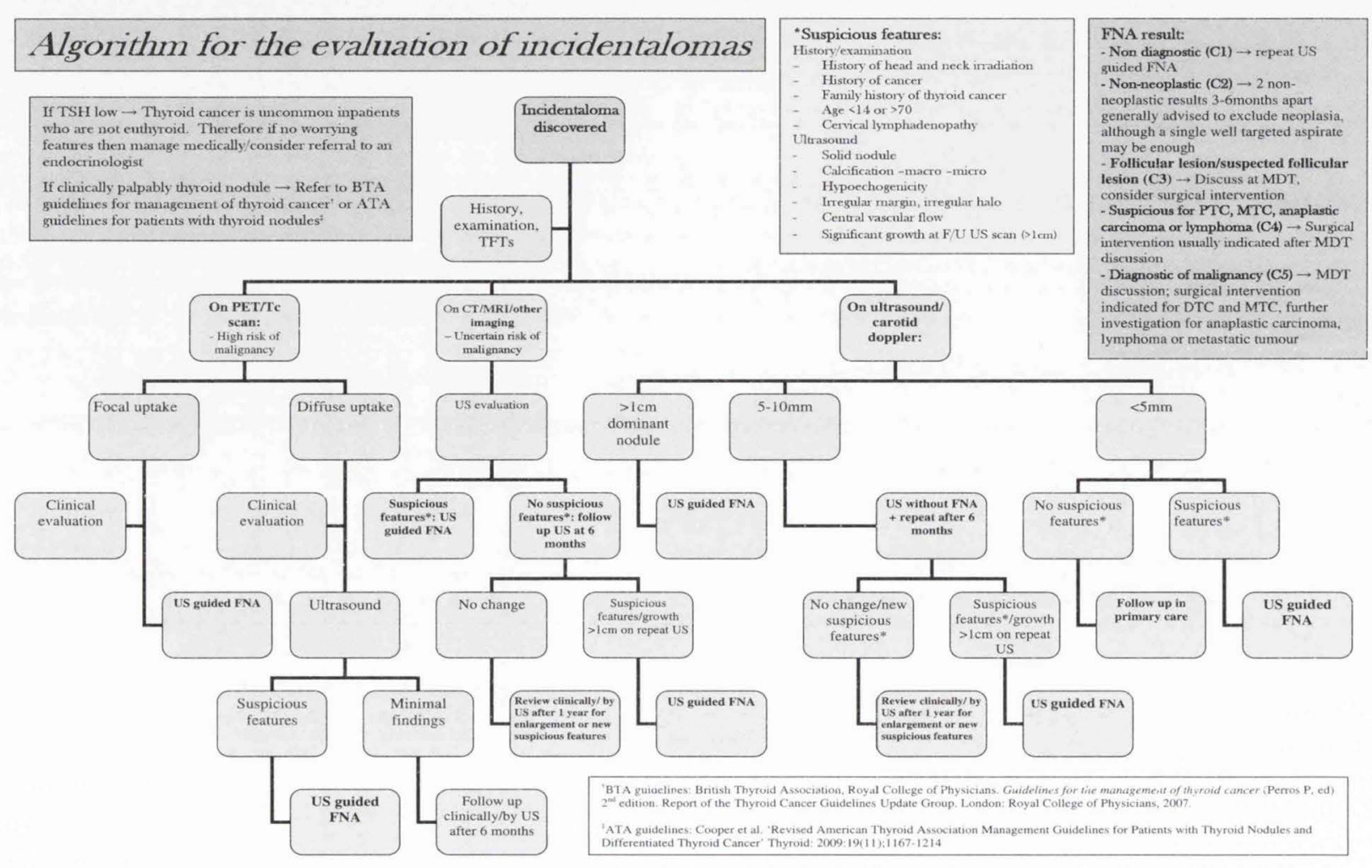

